\title{
Growth and reproduction of Rhynchoplax coralicola Rathbun (Brachyura: Hymenosomatidae)
}

\section{Tianxiang Gao, Shinji Tsuchida and Seiichi Watanabe}

\begin{abstract}
The growth and reproduction of Rhynchoplax coralicola were investigated from March 1993 to April 1994 at the Banda Marine Laboratory of Tokyo University of Fisheries, Chiba Prefecture, Japan. Ovigerous females were found from June to September with a peak in July-August. After the puberty molt, secondary sexual characteristics appear in the abdomen of females and in the chelae of males. The clutch size of ovigerous females ranged from 23 to 220 eggs with a significant increase in diameter of eyed eggs over non-eyed eggs. Juveniles recruit from September, growing slowly over winter and spring but from March to June they grow rapidly, maturing during May to July. After the reproductive period few adults were observed. It is suggest that the maximum life span of $R$. coralicola must be about one year in this study area.
\end{abstract}

\section{Introduction}

Rhynchoplax coralicola belongs to the family Hymenosomatidae. This crab is a very small species, the largest carapace width is about $4.0 \mathrm{~mm}$. $R$. coralicola is widely distributed in Japan, being found at localities from Aomori Prefecture, along the Pacific and Japan Sea coasts of Japan and on the coasts of Taiwan and Singapore (Sakai, 1976). The crab inhabits areas covered by seaweed, usually in the rocky tidal zone at Banda, Chiba Prefecture, Japan.

In Brachyura there are two patterns of mating. One occurs immediately after the female molts when her exoskeleton is still soft, the other pattern occurs whilst the exoskeleton of the female is hard. In Hymenosoma orbiculare, which belongs to the same family as $R$. coralicola (Hymenosomatidae), copulation takes place between intermolt males and soft shelled, newly molted females (Murai, 1987). After copulation, the female $H$. orbiculare is guarded by the male for a considerable time, sometimes more than a day (Broekhuysen, 1955). After mating the spermatophores are stored in the spermathecae and the spermatozoa are retained until egg-laying when fertilization takes place. In many species of crabs the stored sperm can fertilize several batches of eggs from a single mating (Hartnoll, 1985). In some species of the family Majidae, the pubertal molt of females is the terminal molt and they do not grow any further (Hartnoll, 1963). In Halicarcinus australis females isolated from males spawned several times in the laboratory (Lucas and Hodgkin, 1970).

The breeding and growth of $H$. orbiculare in South Africa are described by Broekhuysen (1955). The breeding season of $H$. orbiculare is from late summer to winter (May to December), and covers a period of eight months. A considerable number of very small $H$. orbiculare appeared in the September samples. Based on Walker (1969), the number of broods hatched by an individual of Amarinus lacustris in one season is about three, berried females appear in winter (July) to midsummer (February). By midspring (October), the first juveniles appear.

In four species of Hymenosomatidae: Rhynchoplax messor (Terada, 1977; 

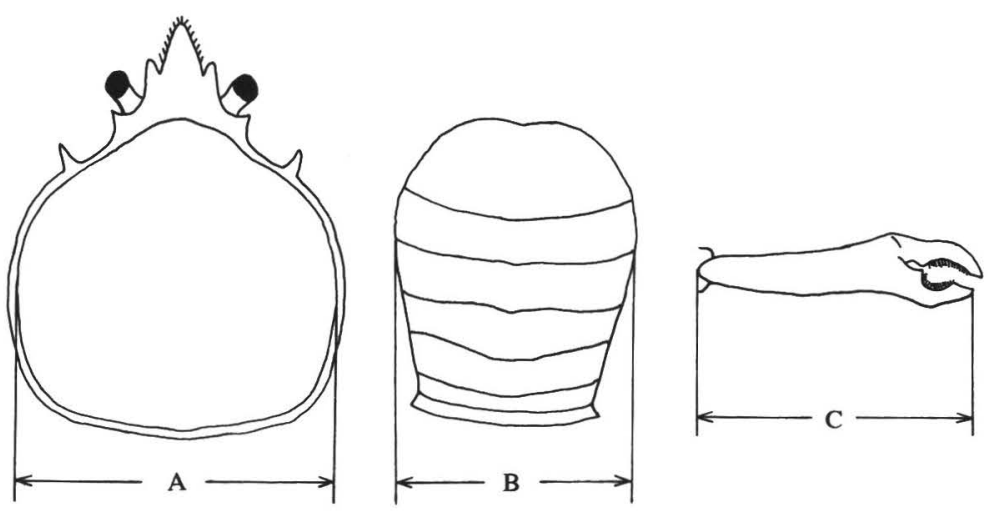

Fig. 1. Measurements of Rhynchoplax coralicola, A: carapace width (CW); B: abdomen width (AW); C: chela length (CL).

Muraoka, 1977, 1980), R. coralicola (Terada, 1977; Muraoka, 1980), Halicarcinus orientalis (Terada, 1977; Muraoka, 1977, 1980) and Elamena truncata (Terada, 1977), there are three zoeal stages. For $R$. coralicola it takes three days to the first zoea, six days to the second zoea and four days to the third zoea. After thirteen days, the zoea molts to the juvenile crab because Hymenosomatids do not have a megalopa. In this way, absence of a megalopa stage is a notable feature for this family (Lucas, 1980).

The growth and reproduction of Hymenosomatidae are poorly documented. This paper deals with the growth and reproductive pattern of $R$. coralicola and details the life history strategy.

\section{Materials and Methods}

Specimens attached to algae (Hizikia fusiformis, Corallina pilulifera, etc.) were collected by hand and the crabs were removed by forceps. Random samples of crabs were collected monthly from March 1993 to April 1994 from rocky and weedy intertidal areas and tidal pools near the Banda Marine Laboratory of Tokyo University of Fisheries, Chiba Prefecture, Japan.

The samples collected were fixed and stored in $10 \%$ sea-water formaldehyde so- lution. Male $R$. coralicola was distinguished from females by the first abdominal appendage. The following were measured to the nearest $0.05 \mathrm{~mm}$ by microscope: carapace width (CW), abdomen width (AW), chela length (CL) (Fig. 1). Based on the AW vs CW of females and CL vs CW of males, relative growth of secondary sexual characteristics was expressed by regression analysis. For all ovigerous females the number of eggs was counted. To estimate mean egg size, the long and short diameters of about 30 eggs for each female were measured to the nearest $0.01 \mathrm{~mm}$ using a Nikon profile projector V-12.

\section{Results}

\section{Growth}

The total number of specimens collected was 778 males and 683 females. The maximum carapace width of males was $4.00 \mathrm{~mm}$ and for females $3.90 \mathrm{~mm}$. The minimum carapace width of males was $0.70 \mathrm{~mm}$ and for females $0.80 \mathrm{~mm}$. In March 1993, the mean carapace width of males was $2.03 \mathrm{~mm}$ and for females 1.84 $\mathrm{mm}$ and by June $3.19 \mathrm{~mm}$ for males, 2.92 $\mathrm{mm}$ for females. In August the mean carapace width reached maximum size of 3.31 $\mathrm{mm}$ for males and $3.10 \mathrm{~mm}$ for females. In September, juveniles were observed with 




Fig. 2. Seasonal change in the average carapace width of Rhynchoplax coralicola. Vertical bars indicate standard deviation.

the proportion of large individuals decreasing and that of small individuals increasing. From November, no male adults were found and female adults only occurred sporadically. In September the mean carapace width of crabs recruited in 1993 was minimal, $1.28 \mathrm{~mm}$ for males and for females $1.09 \mathrm{~mm}$. From November to March 1994, the mean carapace width for both sexes increased slowly (Fig. 2).

There is a difference in growth rate during the warmer and colder months (Table 1). During the period March to June, male crabs grew at $0.39 \mathrm{~mm}$ per month and $0.36 \mathrm{~mm}$ per month for females, from June to September they grew at $0.00 \mathrm{~mm}$ per month and $0.06 \mathrm{~mm}$ per month for females. During September to December male and female juveniles grew at $0.18 \mathrm{~mm}$ per month, but males grew slowly at $0.06 \mathrm{~mm}$ per month from
December to April and $0.00 \mathrm{~mm}$ per month for females.

\section{Reproduction}

Of a total of 683 females, 130 were ovigerous. Ovigerous females were observed from June to October. The range of carapace widths of ovigerous females was $2.85 \mathrm{~mm}$ to $3.75 \mathrm{~mm}$ in June, $2.45 \mathrm{~mm}$ to $3.90 \mathrm{~mm}$ in July, $2.65 \mathrm{~mm}$ to $3.55 \mathrm{~mm}$ in August, and $2.75 \mathrm{~mm}$ to $3.50 \mathrm{~mm}$ in September. In October, only one ovigerous female was found and her carapace width was $2.85 \mathrm{~mm}$. The percentage of ovigerous females was $37.5 \%$ in June, $84.5 \%$ in July and $100 \%$ in August and September and the single specimen in October. The main ovigerous period is from July to August (Fig. 3).

The clutch size of ovigerous females ranged from 23 to 220 (Fig. 4). The average number of eggs was 109 for non-eyed eggs and 103 for eyed eggs. This difference is not significant and female size does not explain any of the variation in clutch size. The long diameter of eggs ranged from $0.27 \mathrm{~mm}$ to $0.45 \mathrm{~mm}$, the average was $0.34 \mathrm{~mm}(\mathrm{SD}=0.02 \mathrm{~mm})$ for non-eyed eggs and $0.36 \mathrm{~mm}(\mathrm{SD}=0.01$ $\mathrm{mm}$ ) for eyed eggs. The short diameter of eggs ranged from $0.26 \mathrm{~mm}$ to $0.40 \mathrm{~mm}$, the average was $0.32 \mathrm{~mm}(\mathrm{SD}=0.02 \mathrm{~mm})$ for non-eyed eggs and $0.34 \mathrm{~mm}(\mathrm{SD}=0.01$ $\mathrm{mm}$ ) for eyed eggs. There is a significant difference in diameter between eyed eggs and non-eyed eggs (t-test, $\mathrm{p}<0.01$ ).

\section{Relative growth}

The relationship between the chela length (CL) and carapace width (CW) of males is indicated by two regression curves depending on the ratio of $\mathrm{CL} / \mathrm{CW}$ (Fig. 5). The data was divided into two groups:

$$
\begin{aligned}
& \text { For CL/CW } \leqq 1.16, \\
& \mathrm{CL}=0.65 \mathrm{CW}^{1.29}, \mathrm{r}=0.97, \mathrm{n}=630(\mathrm{r} \\
& \text { indicates correlation coefficient for } \\
& \text { logarithmic transformed data), } \\
& \text { and for } \mathrm{CL} / \mathrm{CW}>1.16, \\
& \mathrm{CL}=1.09 \mathrm{CW}^{1.26}, \mathrm{r}=0.86, \mathrm{n}=102 .
\end{aligned}
$$




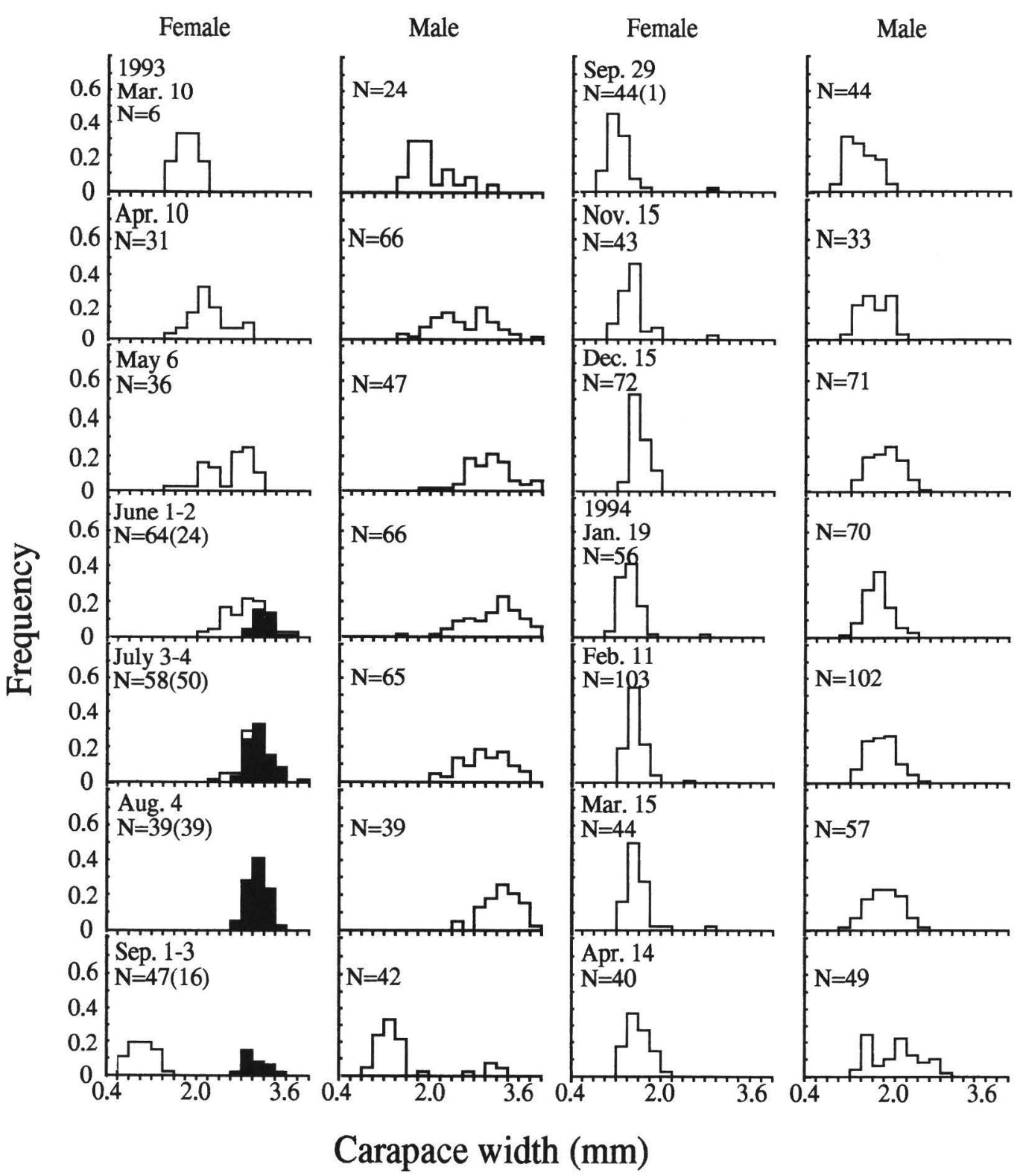

Fig. 3. Seasonal change of the size distribution of Rhynchoplax coralicola from March 1993 to April 1994. Sample size in brackets and shaded bars indicate ovigerous females.

The difference between the two curves is statistically significant (ANCOVA, $\mathrm{p}<$ 0.01 ), but the slope indicates that male cheliped length remains positively allometric (slope>1.0) throughout life.

For females, there is no marked increase in chela length. A single regression curve best fitted the data:

$$
\mathrm{CL}=0.72 \mathrm{CW}^{0.95}, \mathrm{r}=0.99, \mathrm{n}=645 \text {. }
$$

In contrast to males growth of female chelipeds is isometric or possibly negatively allometric because the slope is less than 1.0 .

In the relationship between female abdomen width (AW) and carapace width, there is a considerable increase in abdo- 


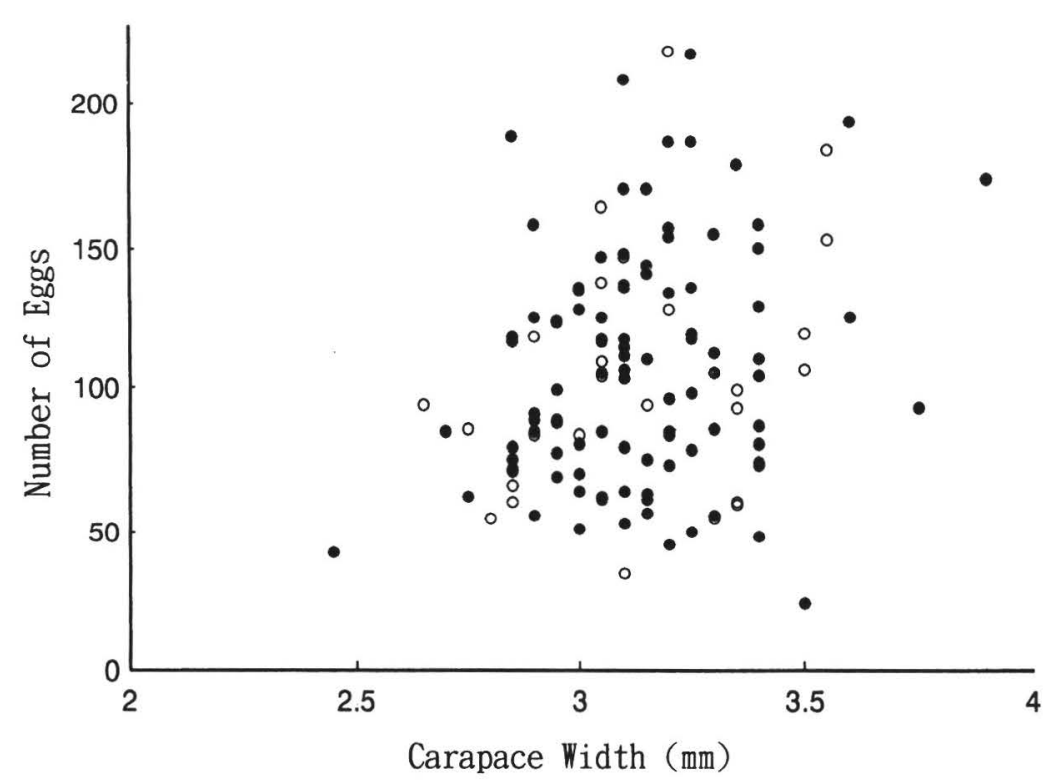

Fig. 4. Relation between clutch size and carapace width of Rhynchoplax coralicola. Solid circles indicate non-eyed eggs and open circles eyed eggs.

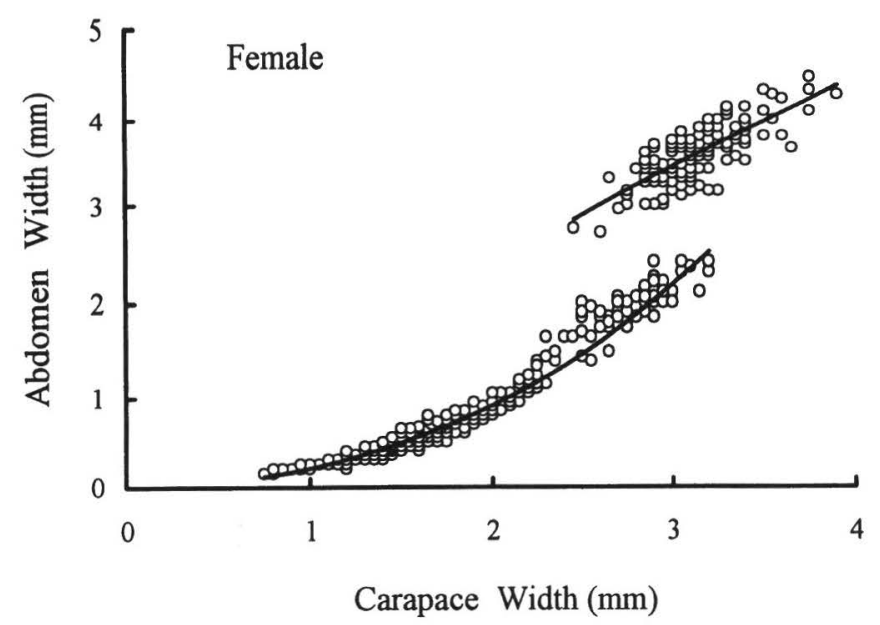

Fig. 5. Relative growth in chela length against carapace width of male Rhynchoplax coralicola. Upper curve fitted to mature males $(\mathrm{CL} / \mathrm{CW}>1.16)$ and the lower curve fitted immature males

men width. Based on the ratio of $\mathrm{AW} / \mathrm{CW}$, it was expressed by separate regression curves (Fig. 6). The data was divided into two groups at $\mathrm{AW} / \mathrm{CW}=0.95$ :

For $\mathrm{AW} / \mathrm{CW} \leqq 0.95$,

$\mathrm{AW}=0.21 \mathrm{CW}^{2.14}, \mathrm{r}=0.98, \mathrm{n}=541$, and for AW/CW > 0.95, in which all females were in berry,

$$
\mathrm{AW}=1.22 \mathrm{CW}^{0.95}, \mathrm{r}=0.77, \mathrm{n}=142 \text {. }
$$

The difference of these two curves is statistically significant (ANCOVA, p < 0.01). The abdomen of immature females is positively allometric (slope $>1.0$ ) but once they mature growth is negatively allometric (slope<1.0).

For males there is no marked increase 


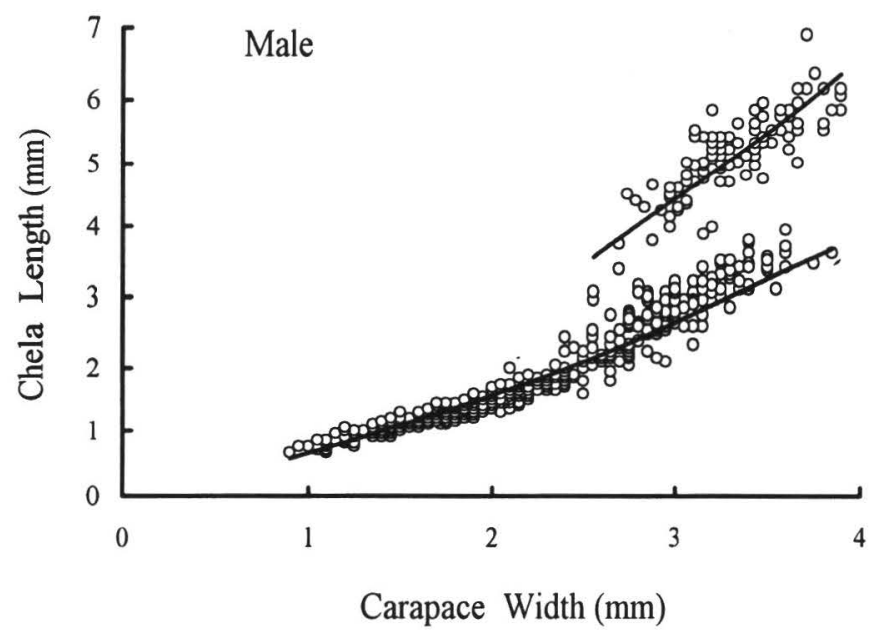

Fig. 6. Relative growth in abdomen width against carapace width of female Rhynchoplax coralicola. Upper curve fitted to mature females (AW/CW $>0.95$ ) and the lower curve fitted immature females $(\mathrm{AW} / \mathrm{CW} \leqq 0.95)$.

in abdomen width. One regression curve closely fitted the data:

$$
\mathrm{AW}=0.21 \mathrm{CW}^{0.86}, \mathrm{r}=0.93, \mathrm{n}=776 \text {. }
$$

Relative growth of the male abdomen is negatively allometric (slope<1.0).

\section{Discussion}

According to Terada (1977) and Muraoka (1977), the duration of first zoea to first stage crabs of $R$. coralicola only takes 13 days. The carapace width of newly metamorphosed juvenile $R$. messor is 0.72 $\mathrm{mm}$ and the carapace length (including rostrum) of first zoea of $R$. coralicola is $0.54 \mathrm{~mm}$ (Terada, 1977; Muraoka, 1977, 1980). The smallest crab of $R$. coralicola obtained in the field was $0.70 \mathrm{~mm}$ for males and $0.80 \mathrm{~mm}$ for females, and we suggest that these crabs had just metamorphosed from zoea to juvenile. In September 1993 a considerable number of very small crabs appeared. Crabs grew fast from March to June, and from June to September they became mature and stopped growing. Juveniles grew faster from September to December, but during the period December to April they grew very slowly (Table 1 ).

In some species of Majidae, such as
Hyas spp., Inachus spp., Macropodia spp., and Eurynome spp, the pubertal molt occurs at the same time as the terminal molt (Hartnoll, 1963). The same growth pattern was found in Tiarinia cornigera (Tsuchida \& Watanabe, 1991) and females of Pugettia quadridens quadridens (Fuseya \& Watanabe, 1993) at the same study area as $R$. coralicola. In Halicarcinus species the pubertal molt was also the terminal molt in both sexes (Lucas and Hodgkin, 1970). R. coralicola matured in June and July, and ovigerous females occurred from June to October. During the reproductive season, molting of mature crabs was not observed, and after the reproductive season almost all of the adults died. So it seems that the pubertal molt for $R$. coralicola is terminal.

The pubertal molt is associated with the development of secondary sexual characteristics separating the immature and mature phases of $R$. coralicola. Like most crabs, secondary sexual characteristics of $R$. coralicola appear very clearly in abdomen width for females and in chela length for males. Often, relative growth is expressed by two regression lines, for example, T. cornigera (Tsuchida \& Watanabe, 1991) and $P$. quadridens quadri- 
Table 1. Growth rates (mm per month) of Rhynchoplax coralicola from March 1993 to April 1994. Growth rate indicates increment of the average carapace width from the beginning to the end of the period.

\begin{tabular}{ccccc}
\hline \hline Sex & Mar.-Jun. & Jun.-Sep. & Sep.-Dec. & Dec.-Apr. \\
\hline Male & 0.39 & 0.00 & 0.18 & 0.06 \\
Female & 0.36 & 0.06 & 0.18 & 0.00 \\
\hline
\end{tabular}

dens for females (Fuseya \& Watanabe, 1993). Secondary sexual characteristics of $R$. coralicola was expressed by two regression curves which were significantly different. From September to July (mainly from September to next March), most of the crabs were immature, the abdomen of females and chela of males were relatively smaller than that of mature adults. After the pubertal molt, during May to September (mainly in July and August), the abdomen of females and the chela of males increased markedly, becoming broader and bigger.

After mating females store spermatophores in the spermathecae. In many species of Majidae, females spawn several times from a single mating (Hartnoll, 1985). Ovigerous females of Microphrys bicornutus spawned four times (Hartnoll, 1965). Ovigerous females of $T$. cornigera reared in the laboratory spawned one to six times in a reproductive season (Tsuchida \& Watanabe, 1991). Females of $P$. quadridens quadridens spawned several times during the reproductive season (Fuseya \& Watanabe, 1993). Also in $H$. orbiculare ovigerous females could produce as many as three normal batches of eggs (Broekhuysen, 1955). Similarly, $R$. coralicola had the same disposition and spawned several times. According to our rearing experiment, $R$. coralicola spawned two times and the incubation period was about 15 days in laboratory, so it is suggested that $R$. coralicola can spawn as many as about six times in the reproductive season (about 3 months). But by the end of the reproductive season the percentage of ovigerous females decreased, so we estimate that females of $R$. coralicola can spawn 3-4 times in a repro- ductive season. Approximate numbers of eggs per egg mass in ovigerous Hymenosomatid females from marine and brackish environments were $30-3200$ eggs and the diameter ranged from 0.25 to $0.45 \mathrm{~mm}$ (Lucas, 1980). The clutch size of $R$. coralicola was about 107 eggs $(\mathrm{SD}=42)$ and the diameter was about $0.36 \mathrm{~mm}$. There were few eggs but the diameter was relatively larger. The average number of eyed eggs was slightly less than that of non-eyed eggs and the diameter of eyed eggs was bigger than that of non-eyed eggs. There was not a significant difference between non-eyed eggs and eyed eggs, therefore we can conclude that there is little or no egg mortality during incubation.

Based on our research, an outline of the life history of $R$. coralicola is illustrated in Fig. 7. The life history is similar to that of Tiarinia cornigera (Tsuchida \& Watanabe, 1991). The larvae of $R$. coralicola hatch in June to September and they metamorphose to juvenile in about thirteen days. The juvenile appears in September. In December the average carapace width of $R$. coralicola is $1.62 \mathrm{~mm}$ for females and $1.83 \mathrm{~mm}$ for males. From December to April, $R$. coralicola shows a slow growth rate, but grows rapidly in the next spring. In June, average carapace width is $2.92 \mathrm{~mm}$ for females and $3.19 \mathrm{~mm}$ for males and they reach maturity and stop growing. The pubertal molt occurs at the same time as the terminal molt, and is accomplished in May to July. Mating and spawning occur by September and females spawn several times in a breeding season. In October, the adults finish breeding and die off. The life span of $R$. 


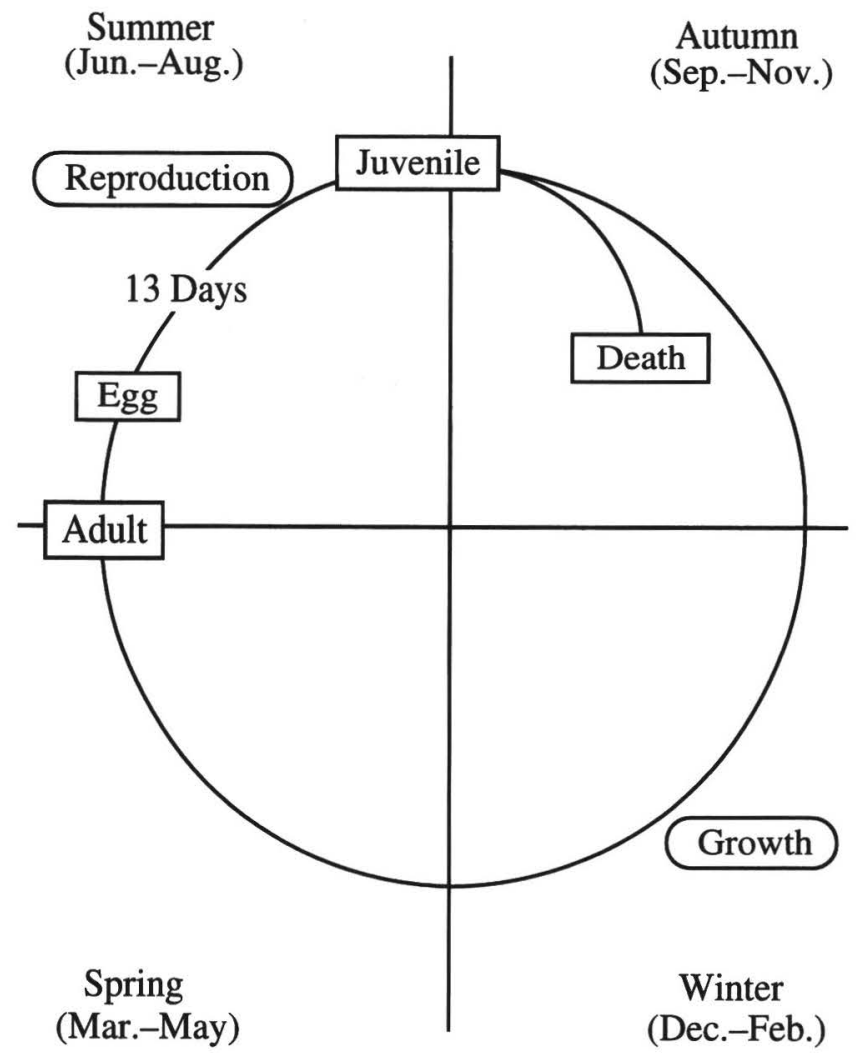

Fig. 7. Life history of Rhynchoplax coralicola. In summer, adults spawn and then die out. From September, juveniles appear, grow and become adults by the next summer.

coralicola is suggested to be about one year. This means that $R$. coralicola is one of the shortest-living crabs known at present.

\section{Acknowledgements}

We thank Dr. Christopher P. Norman, Tokyo University of Fisheries, for his helpful suggestions and reading a draft of the manuscript. We also thank Dr. Colin L. McLay, University of Canterbury, for his critical review of the manuscript.

\section{Literature Cited}

Broekhuysen, G. J., 1955. The breeding and growth of Hymenosoma orbiculare Desm. (Crustacea, Brachyura). Annals of the South African Museum. 28: 331-366.

Fuseya, R. \& Watanabe, S., 1993. Growth and reproduction of the spider crab, Pugettia quadridens quadridens (De Haan) (Brachyura: Majidae). Crustacean Research, 22: 75-81.

Hartnoll, R. G., 1963. The biology of Manx spider crabs. Proceedings of the Zoological Society of London, 141: 445-496.

-, 1974 . Variation in growth pattern between some secondary sexual characters in crabs. Crustaceana, 27: 131-136. 1985. Growth, sexual maturity and reproduction output. Pp.101-128. In: Wenner A. M. (ed.), Crustacean Issue 3. Factors in Adult growth. xiii + 362 pp., A. A. Balkema, Rotterdam.

Lucas, J. S., 1980. Spider crabs of the family Hymenosomatidae (Crustacea, Brachyura) with particular reference to Australian species: systematics and biology). Records of the Australian Museum, Vol. 33, No. 4: 148-247.

- , and Hodgkin E. P., 1970a. Growth and reproduction of Halicarcinus australis (Haswell) (Crustacea, Brachyura) in the 
Swan estuary, Western Australia. 1. Crab instars. Australian Journal of Marine and Freshwater Research, 21 (2): 149-162.

Murai, M., 1987. Mating and sperm storage in crabs. Marine science, (In Japanese: Kanirui no Kobi to Mesu ni yoru Seishi Hozon. Kaiyokagaku), 2: 118-122.

Muraoka, K., 1977. The larval stages of Halicarcinus orientalis Sakai and Rhynchoplax messor Stimpson reared in the laboratory (Crustacea, Brachyura, Hymenosomatidae). Zoological Magazine, 86: 94-99.

, 1980. Larvae of crabs (In Japanese: Kanirui no Yosei): Rhynchoplax coralicola Rathbun, Rhynchoplax messor Stimpson, Halicarcinus orientalis Sakai. Aquabiology, 10: 364-365.

Sakai, T., 1976. Crabs of Japan and the Adjacent Seas. Kodansha, Tokyo. [In 3 volume: (1) English text, xxix + 149 pp. (2) Plate volume, 46 pp., 251 pls. (3) Japanese text, $93 \mathrm{pp}$. ]

Terada, M., 1977. On the zoea larvae of four crabs of the family Hymenosomidae. Zoological Magazine, 86: 174-184.

Tsuchida, S., \& Watanabe, S., 1991. Growth and reproduction of the spider crab, Tiarinia cornigera (Latreille) (Brachyura: Majidae). Researches on Crustacea, 20: 43-55.

Walker, k., 1969. The ecology and distribution of Halicarcinus lacustris (Brachyura: Hymenosomatidae) in Australian inland waters. Australian Journal of Marine and Freshwater Research, 20(2): 163-173.

Department of Aquatic Biosciences, Tokyo University of Fisheries, Konan, Minato, Tokyo 108, Japan. 